\title{
Polymorphisms of DNA repair-related genes with susceptibility and prognosis of prostate cancer
}

\author{
X.J. Zhang, P. Liu and F. Zhu \\ Urology Department, \\ The First Affiliated Hospital of Xinxiang Medical University, \\ Weihui, Henan, China \\ Corresponding author: X.J. Zhang \\ E-mail: zhangxinjun_xmu@163.com \\ Genet. Mol. Res. 13 (2): 4419-4424 (2014) \\ Received August 20, 2013 \\ Accepted November 29, 2013 \\ Published January 24, 2014 \\ DOI http://dx.doi.org/10.4238/2014.January.24.20
}

\begin{abstract}
We aimed to investigate the association between genetic variants of the DNA repair genes XPG, CSB, XPC, CCNH, and MMS19L in the nucleotide excision repair (NER) pathway and risk of prostate cancer in a population in China. This study included 229 patients with newly diagnosed and histopathologically confirmed primary prostate cancer and 238 healthy controls. Genotyping of $X P G, C S B, X P C, C C N H$, and MMS19L were performed on a 384-well plate on the MassARRAY platform. Associations between the polymorphisms of the six genes and risk of prostate cancer were analyzed using conditional logistical regression. We found that the variant genotype TT of the XPG rs2296147 polymorphism was moderately significantly associated with a higher risk of prostate cancer compared to the wild-type genotype $\mathrm{CC}$ [odds ratio (OR) $=1.79,95 \%$ confidence interval $(\mathrm{CI})=1.01-3.25]$, and individuals carrying the GG genotype of the CSB rs2228526 polymorphism were associated with an increased risk of prostate cancer $(\mathrm{OR}=1.95,95 \% \mathrm{CI}=1.02-3.74)$. The combination genotype of the XPG T allele and the CSB G allele was associated with a moderately higher risk of prostate cancer risk $(\mathrm{OR}=1.84$, $95 \% \mathrm{CI}=1.06-3.20)$. In conclusion, we found that polymorphisms in XPG rs2296147 and CSB rs2228526 were significantly associated with prostate
\end{abstract}


cancer susceptibility in the Chinese population analyzed. Our results support the hypothesis that naturally occurring genetic variation of DNA repair genes increases susceptibility to prostate cancer.

Key words: $X P G ; C S B$; DNA repair-related genes; Prostate cancer

\section{INTRODUCTION}

Prostate cancer is the second most commonly diagnosed solid tumor and the fifth most common cancer worldwide, accounting for $10 \%$ of all male cancer-related deaths (Globocan, 2008). The etiology of prostate cancer is unknown, and it is a multi-factorial disease that is caused by both genetic and environmental factors (Lichtenstein et al., 2000). The risk of prostate cancer increases with age, which reflects the accumulation of DNA damage due to oxidative stress, inflammation, and environmental carcinogens as well as a reduced DNA damage repair capacity (Bostwick et al., 2000; Pathak et al., 2005; Khandrika et al., 2009).

DNA repair mechanisms are important pathways for the removal of oxidative DNA compounds or DNA adducts from damaged genomic sites. There are a number of DNA repair pathways responsible for repairing various types of DNA damage, including base excision repair (BER), nucleotide excision repair (NER), double-strand break repair, and homologous recombination repair (HRR). BER, NER, and HRR constitute the main defenses against lesions generated by ionizing radiation, alkylating agents, and reactive oxygen species (Smith et al., 2003). Variations in DNA repair genes may affect the capacity of encoded DNA repair enzymes to effectively remove DNA adducts or lesions, and subsequently enhance the risk of cancer (Goode et al., 2002; Hu et al., 2002, 2004).

Previous studies have examined the association between single-nucleotide polymorphisms (SNPs) in DNA repair genes and the risk of prostate cancer in various populations (Hyytinen et al., 1999; Hooker et al., 2008; Berhane et al., 2012). However, the results of these studies are inconsistent due to different populations, case selections, and sample sizes. Therefore, we aimed to investigate the association between genetic variants of XPG, CSB, XPC, $C C N H$, and MMS19L in the NER pathway and risk of prostate cancer in a population in China.

\section{MATERIAL AND METHODS}

\section{Characteristics of study subjects}

The subjects were recruited from an ongoing multicenter case-control study being conducted in China. This study included 247 patients with newly diagnosed and histopathologically confirmed primary prostate cancer from the Shanghai Pudong New Area Zhoupu Hospital and the Shanghai East Hospital Affiliated to Tongji University between January 2008 and May 2012. A total of 229 prostate cancer patients agreed to participate with a participation rate of $92.7 \%$. A total of 264 cancer-free controls, who sought health examinations at the Shanghai Pudong New Area Zhoupu Hospital and the Shanghai East Hospital Affilated to Tongji University, were selected during the same time period, and 238 individuals agreed to participate (participation rate: $90.2 \%$ ). Controls were age-matched ( \pm 5 years) to cases. All subjects were asked to provide $5 \mathrm{~mL}$ blood for genotyping and signed written informed consent. 


\section{SNP selection and genotyping}

Five milliliters of venous blood was drawn from each case and control. The blood was kept at $-20^{\circ} \mathrm{C}$, and $1.5-2.2 \mathrm{mg} / \mathrm{mL}$ ethylenediaminetetraacetic acid (EDTA) was used as anticoagulant. The DNA was extracted using a TIANamp blood DNA kit (Tiangen Biotech, Beijing, China). Genotyping of the XPG rs2296147, XPG rs2094258, CSB rs2228526, XPC rs2228001, CCNH rs2266690, and MMS19L rs29001322 polymorphisms were performed on a 384-well plate on the MassARRAY platform (Sequenom, San Diego, CA, USA), which combined polymerase chain reaction (PCR) and matrix-assisted laser desorption ionization-time of flight (MALDI-TOF) mass spectrometry technologies. PCR and single-base extension primers were designed using the Sequenom Assay Design 3.1 software (Sequenom) according to manufacturer instructions. The cycling program involved preliminary denaturation at $94^{\circ} \mathrm{C}$ for $2 \mathrm{~min}$, followed by 35 cycles of denaturation at $94^{\circ} \mathrm{C}$ for $30 \mathrm{~s}$, and annealing at $64^{\circ} \mathrm{C}$ for $30 \mathrm{~s}$, with a final extension at $72^{\circ} \mathrm{C}$ for $10 \mathrm{~min}$. PCR products were verified by $1.0 \%$ agarose gel electrophoresis, and the PCR products were visualized using ethidium bromide staining. For quality control, genotyping was repeated for a random sample of $5 \%$ of the cases and controls, and the results were $100 \%$ concordant.

\section{Statistical analysis}

All statistical analyses were performed using the SAS software (version 9.1; SAS Institute, Cary, NC, USA). Continuous variables are reported as means $\pm \mathrm{SD}$ and were analyzed using the independent sample Student $t$-test. Categorical variables are reported as the proportion of subjects (\%) and were analyzed using the $\chi^{2}$ test. The Hardy-Weinberg equilibrium and between-group comparisons of genotype distributions were analyzed using a goodness-of-fit $\chi^{2}$ test. Odds ratios (ORs) and their corresponding 95\% confidence intervals (CIs) were used to assess the effect of each SNP on prostate cancer risk. Unconditional multivariate logistic regression models were adopted to calculate the OR $(95 \% \mathrm{CI})$ after adjusting for age, family history of prostate cancer, smoking status, drinking status, and body mass index (BMI). All comparisons were two-sided, and $\mathrm{P}<0.05$ was regarded as statistically significant.

\section{RESULTS}

The mean ages of the cases and controls were $66.7 \pm 8.2$ years and $67.3 \pm 7.5$ years, respectively (Table 1). We did not find a significant effect of smoking status, drinking status, or BMI on the risk of prostate cancer. However, we found that prostate cancer cases were more likely to have a family history of cancer compared with the controls (7.5 vs $0.8 \%, \mathrm{P}<0.05)$.

The genotype distributions of the $X P G$ rs2296147 and $C S B$ rs2228526 SNPs were significantly different between cases and controls (Table 2). Associations between the polymorphisms of the six genes and risk of prostate cancer were analyzed using conditional logistical regression, with frequency matched by age. For XPG rs2296147, the variant genotype TT was moderately significantly associated with a higher risk of prostate 
cancer when compared to the wild-type genotype $\mathrm{CC}$, with an adjusted $\mathrm{OR}(95 \% \mathrm{CI})$ of 1.79 (1.01-3.25). For CSB rs2228526, individuals carrying the GG genotype were associated with an increased risk of prostate cancer $(\mathrm{OR}=1.95,95 \% \mathrm{CI}=1.02-3.74)$.

\begin{tabular}{|c|c|c|c|c|c|c|}
\hline Characteristics & Cases & $\%$ & Controls & $\%$ & $\chi^{2}$ value & $\mathrm{P}$ value \\
\hline Age (years, means $\pm S D$ ) & $66.7 \pm 8.2$ & & $67.3 \pm 7.5$ & & & \\
\hline$<65$ & 81 & 35.4 & 90 & 37.8 & & \\
\hline$\geq 65$ & 148 & 64.6 & 148 & 62.2 & 0.3 & 0.584 \\
\hline \multicolumn{7}{|l|}{ Smoking status } \\
\hline Non-smoker & 143 & 62.4 & 166 & 69.7 & & \\
\hline Smoker & 86 & 37.6 & 72 & 30.3 & 2.78 & 0.09 \\
\hline \multicolumn{7}{|l|}{ Drinking status } \\
\hline Non-drinker & 153 & 66.8 & 172 & 72.3 & & \\
\hline Drinker & 76 & 33.2 & 66 & 27.7 & 1.64 & 0.2 \\
\hline \multicolumn{7}{|l|}{ Body mass index $\left(\mathrm{kg} / \mathrm{m}^{2}\right)$} \\
\hline$<23$ & 140 & 61.3 & 143 & 60.1 & & \\
\hline$\geq 23$ & 89 & 38.7 & 95 & 39.9 & 0.05 & 0.82 \\
\hline \multicolumn{7}{|c|}{ Family history of prostate cancer } \\
\hline No & 17 & 7.5 & 2 & 0.8 & & \\
\hline Yes & 212 & 92.5 & 236 & 99.2 & 12.9 & $<0.001$ \\
\hline
\end{tabular}

Table 2. Genotype distributions and association with prostate cancer.

\begin{tabular}{|c|c|c|c|c|c|c|}
\hline Gene & Cases & $\%$ & Controls & $\%$ & OR $(95 \% \mathrm{CI})^{1}$ & $P$ value \\
\hline \multicolumn{7}{|c|}{$\overline{X P G ~ r s 2296147}$} \\
\hline $\mathrm{CC}$ & 143 & 62.3 & 167 & 70.2 & - & - \\
\hline CT & 49 & 21.2 & 46 & 19.3 & $1.28(0.79-2.07)$ & 0.29 \\
\hline TT & 38 & 16.5 & 25 & 10.5 & $1.79(1.01-3.25)$ & 0.04 \\
\hline \multicolumn{7}{|c|}{$X P G$ rs 2094258} \\
\hline AA & 93 & 40.7 & 105 & 44.1 & - & - \\
\hline $\mathrm{AG}$ & 75 & 32.6 & 75 & 31.4 & $1.13(0.72-1.77)$ & 0.57 \\
\hline GG & 61 & 26.7 & 58 & 24.5 & $1.19(0.74-1.92)$ & 0.46 \\
\hline \multicolumn{7}{|c|}{$C S B$ rs 2228526} \\
\hline $\mathrm{AA}$ & 90 & 39.5 & 113 & 47.4 & - & - \\
\hline $\mathrm{AG}$ & 105 & 45.7 & 103 & 43.2 & $1.52(0.81-2.92)$ & 0.17 \\
\hline GG & 34 & 14.8 & 22 & 9.4 & $1.95(1.02-3.74)$ & 0.03 \\
\hline \multicolumn{7}{|c|}{$X P C$ rs 2228001} \\
\hline AA & 158 & 69.2 & 170 & 71.4 & - & - \\
\hline $\mathrm{AC}$ & 38 & 16.6 & 37 & 15.5 & $1.12(0.65-1.89)$ & 0.69 \\
\hline $\mathrm{CC}$ & 33 & 14.2 & 31 & 13.1 & $1.15(0.65-2.03)$ & 0.62 \\
\hline \multicolumn{7}{|c|}{$C C N H$ rs 2266690} \\
\hline $\mathrm{CC}$ & 159 & 69.3 & 158 & 66.4 & - & - \\
\hline $\mathrm{CT}$ & 40 & 17.4 & 41 & 17.1 & $0.96(0.58-1.63)$ & 0.9 \\
\hline TT & 30 & 13.3 & 39 & 16.5 & $0.76(0.44-1.33)$ & 0.31 \\
\hline \multicolumn{7}{|c|}{ MMS19L rs29001322 } \\
\hline $\mathrm{CC}$ & 99 & 43.4 & 116 & 48.7 & - & - \\
\hline CT & 93 & 40.7 & 92 & 38.7 & $1.19(0.79-1.80)$ & 0.4 \\
\hline TT & 36 & 15.9 & 30 & 12.6 & $1.41(0.78-2.55)$ & 0.23 \\
\hline
\end{tabular}

${ }^{1}$ Adjusted for age and family history of prostate cancer.

A further association analysis was conducted to identify interactions of the susceptibility-associated genes, $X P G$ rs2296147 and CSB rs2228526, and their impact on prostate cancer risk (Table 3 ). The combination genotype of the $X P G \mathrm{~T}$ allele and the CSB $\mathrm{G}$ allele was associated with a moderately higher risk of prostate cancer, with an $\mathrm{OR}(95 \% \mathrm{CI})$ of 1.84 (1.06-3.20). 
Table 3. Interactions of $X P G$ rs 2296147 and $C S B$ rs2228526 in cases and controls on prostate cancer risk.

\begin{tabular}{lcccccc}
\hline Single nucleotide polymorphism & $\begin{array}{c}\text { Cases } \\
(\mathrm{N}=229)\end{array}$ & $\%$ & $\begin{array}{c}\text { Controls } \\
(\mathrm{N}=238)\end{array}$ & $\%$ & OR $(95 \% \mathrm{CI})^{1}$ & P value \\
\hline$X P G$ rs2296147/CSB rs2228526 & & & & & & - \\
CC/AA & 59 & 31.6 & 85 & 33.6 & - & $1.60(0.83-3.07)$ \\
T allele/AA & 31 & 17.4 & 28 & 19.2 & 0.13 \\
CC/G allele & 84 & 36.3 & 82 & 40.2 & $1.48(0.92-2.38)$ & 0.09 \\
T allele/G allele & 55 & 14.7 & 43 & 7.0 & $1.84(1.06-3.20)$ & 0.02 \\
\hline
\end{tabular}

${ }^{1}$ Adjusted for age and family history of prostate cancer.

\section{DISCUSSION}

In this case-control study in a Chinese population, we identified the individual and combined effects of polymorphisms in XPG rs2296147, XPG rs2094258, CSB rs2228526, $X P C$ rs2228001, CCNH rs2266690, and MMS19L rs29001322 on the risk of prostate cancer. We found that $X P G$ rs2296147 and $C S B$ rs2228526 were strongly associated with prostate cancer risk, both individually and in combination.

To the best of our knowledge, our study is the first to describe the associations of these DNA repair gene polymorphisms with prostate cancer risk in a Chinese population. Three previous studies conducted in Indian, Caucasian-American, and African-American populations, respectively, reported associations between the XPG Asp1104His polymorphism and risk of prostate cancer (Hyytinen et al., 1999; Hooker et al., 2008; Berhane et al., 2012). Our findings strongly indicate that polymorphisms in XPG rs2296147 contribute to prostate cancer susceptibility, which is in line with results of previous studies showing that the XPG rs2296147 TT genotype is associated with increased prostate cancer risk. Berhane et al. (2012) reported that the His/His genotype of $X P G$ was associated with a strongly increased risk of prostate cancer in an Indian population, with an OR of 2.53. Another study conducted in the United States reported that $X P G$ Asp1104His plays an important role in the development of prostate cancer (Hyytinen et al., 1999). However, other studies have yielded conflicting results. One population-based study including 254 African-American prostate cancer cases and 301 healthy controls from the United States reported a non-significant association between $X P G$ polymorphisms and the risk of developing prostate tumors (Hooker et al., 2008). The inconsistency of these studies may be explained by differences in genetic background, population background, source of controls, and sample sizes, or due to chance.

Our study found a moderately increased risk of prostate cancer for patients with the $C S B$ rs2228526 GG genotype. Similar associations have been identified for other types of cancer, including skin cancer, bladder cancer, lung cancer, and oral cancer (Chiu et al., 2008; Chang et al., 2009; Ma et al., 2009; Wheless et al., 2012). Polymorphisms in DNA repair genes may be associated with differences in the repair of DNA damage, and thus influence the risk of developing tumors. A recent study in an African-American population found that variants of $C S B$ did not influence the development of prostate cancer (Hooker et al., 2008). Further studies are greatly warranted to confirm these associations. The combination of the $X P G \operatorname{rs} 2296147 \mathrm{~T}$ allele and the $C S B$ rs $2228526 \mathrm{G}$ allele was also strongly associated with prostate cancer in our study. This combination effect could be explained by the additive effect of the two genotypes.

There are two limitations in our study. First, since our study was only conducted in one place, selection bias is inevitable and the results may not be extractable to other popula- 
tions. Second, the sample size in our study was relatively small, which might have reduced the statistical power to detect differences in $X P C, C C N H$, and $M M S 19 L$ between groups. Therefore, further large sample multicenter studies are greatly needed.

In conclusion, we found that polymorphisms in XPG rs2296147 and CSB rs2228526 were significantly associated with prostate cancer susceptibility in the Chinese population, and that the combination of the XPG rs $2296147 \mathrm{~T}$ allele and the $C S B$ rs $2228526 \mathrm{G}$ allele were strongly associated with an increased risk of prostate cancer. Our results support the hypothesis that naturally occurring genetic variation of DNA repair genes increases susceptibility to prostate cancer.

\section{ACKNOWLEDGMENTS}

Research supported by the Leader Program Funds of the Health System in the Pudong District of Shanghai (\#PWRd2011-08), and by the Health Science and Technology Development Fund (\#PW2012A-34).

\section{REFERENCES}

Berhane N, Sobti RC and Mahdi SA (2012). DNA repair genes polymorphism (XPG and XRCC1) and association of prostate cancer in a north Indian population. Mol. Biol. Rep. 39: 2471-2479.

Bostwick DG, Alexander EE, Singh R, Shan A, et al. (2000). Antioxidant enzyme expression and reactive oxygen species damage in prostatic intraepithelial neoplasia and cancer. Cancer 89: 123-134.

Chang CH, Chiu CF, Wang HC, Wu HC, et al. (2009). Significant association of ERCC6 single nucleotide polymorphisms with bladder cancer susceptibility in Taiwan. Anticancer Res. 29: 5121-5124.

Chiu CF, Tsai MH, Tseng HC, Wang CL, et al. (2008). A novel single nucleotide polymorphism in ERCC6 gene is associated with oral cancer susceptibility in Taiwanese patients. Oral Oncol. 44: 582-586.

Globocan (2008). Prostate Cancer Incidence, Mortality and Prevalence Worldwide in 2008. International Agency for Research on Cancer. Available at [http://globocan.iarc.fr/factsheet.asp.]. Accessed January 12, 2013.

Goode EL, Ulrich CM and Potter JD (2002). Polymorphisms in DNA repair genes and associations with cancer risk. Cancer Epidemiol. Biomarkers Prev. 11: 1513-1530.

Hooker S, Bonilla C, Akereyeni F, Ahaghotu C, et al. (2008). NAT2 and NER genetic variants and sporadic prostate cancer susceptibility in African Americans. Prostate Cancer Prostatic Dis. 11: 349-356.

Hu JJ, Mohrenweiser HW, Bell DA, Leadon SA, et al. (2002). Symposium overview: genetic polymorphisms in DNA repair and cancer risk. Toxicol. Appl. Pharmacol. 185: 64-73.

Hu JJ, Hall MC, Grossman L, Hedayati M, et al. (2004). Deficient nucleotide excision repair capacity enhances human prostate cancer risk. Cancer Res. 64: 1197-1201.

Hyytinen ER, Frierson HF Jr, Sipe TW, Li CL, et al. (1999). Loss of heterozygosity and lack of mutations of the XPG/ ERCC5 DNA repair gene at 13q33 in prostate cancer. Prostate 41: 190-195.

Khandrika L, Kumar B, Koul S, Maroni P, et al. (2009). Oxidative stress in prostate cancer. Cancer Lett. 282: 125-136.

Lichtenstein P, Holm NV, Verkasalo PK, Iliadou A, et al. (2000). Environmental and heritable factors in the causation of cancer - analyses of cohorts of twins from Sweden, Denmark, and Finland. N. Engl. J. Med. 343: 78-85.

Ma H, Hu Z, Wang H, Jin G, et al. (2009). ERCC6/CSB gene polymorphisms and lung cancer risk. Cancer Lett. 273: 172-176.

Pathak SK, Sharma RA, Steward WP, Mellon JK, et al. (2005). Oxidative stress and cyclooxygenase activity in prostate carcinogenesis: targets for chemopreventive strategies. Eur. J. Cancer 41: 61-70.

Smith TR, Miller MS, Lohman K, Lange EM, et al. (2003). Polymorphisms of XRCC1 and XRCC3 genes and susceptibility to breast cancer. Cancer Lett. 190: 183-190.

Wheless L, Kistner-Griffin E, Jorgensen TJ, Ruczinski I, et al. (2012). A community-based study of nucleotide excision repair polymorphisms in relation to the risk of non-melanoma skin cancer. J. Invest. Dermatol. 132: 1354-1362. 